\title{
Application of Mining Waste Powder as filler in Hot Mix Asphalt
}

\author{
Sangiorgi Cesare ${ }^{1}$, Tataranni Piergiorgio ${ }^{1, *}$, Lantieri Claudio ${ }^{1}$ and Mazzotta Francesco $^{1}$ \\ ${ }^{1}$ DICAM Roads, University of Bologna, 40136 Bologna, Italy
}

\begin{abstract}
Asphalt concrete mixtures are composed of two main components: aggregates and binder. The fraction of aggregates passing through the $63 \mu \mathrm{m}$ sieve is traditionally considered as filler. During years, several researches have shown the importance and the influence of filler in controlling the physical and mechanical properties of Hot Mix Asphalts (HMAs). The main objective of this research is to investigate and to assess the effects given by the use of Mining Waste Powder (MWP) within HMAs in total substitution of traditional limestone filler. The MWP used in this study is a residual of the tungsten extraction process in Panasqueira (Portugal) mine. The evaluation of properties conferred by the presence of the MWP filler within asphalt mixtures is based on a physical and mechanical laboratory characterization. For this purpose, tests have been performed both on bituminous mastics and on HMAs. Results indicate that the use of MWP in total substitution of limestone filler does not negatively affect the performances of HMAs and their bituminous mastics.
\end{abstract}

\section{Introduction}

According to the last estimates, there are about 38 million of kilometres of paved roads in the world [1]. The EAPA (European Asphalt Pavement Association) stated that over $90 \%$ of the total road network is surfaced with asphalt, for a yearly total production of 275 million tons of asphalt pavement materials. The vast majority of road pavements are made of Hot Mix Asphalt (HMA), due to its high mechanical and functional properties (driving comfort, skid resistance, durability and water resistance). HMAs constituent materials confer these performances; they are generally composed by $90 \%$ of aggregates and by $5 \%$ of bitumen (percentages by its volume). According to EN 13043 standard, in the composition of aggregates grading distribution, the fraction of material passing through the $63 \mu \mathrm{m}$ sieve is considered as filler. During HMAs production, mineral filler is generally added to the aggregates mixture to combine with bitumen and form a bituminous mastic, which significantly influences the final performances of asphalt mixture [2]. Over the years, several researches and studies have shown the high effect of fillers properties on the bituminous mastic performances [3]. From a structural point of view, the presence of filler within the aggregates mixture enhances the reduction of intergranular voids [4]. Thanks to its interaction with the bitumen, it decreases the HMAs thermal susceptibility and promotes the binding between aggregates and bituminous mastic. For these reasons, a complete analysis of a HMA must include a characterization of its bituminous mastic and filler. Several materials have been analysed and proposed as filler for HMAs production over the years. Generally fillers are divided in natural ones (i.e. limestone powder) which derive from crushed rocks, and imported fillers (i.e. lime, Portland cement, ashes and wastes). Nowadays, the growing interest of research on resources conservation and environmental protection has led to study the potential use of recycled materials in road construction [5]. There are in scientific literature many studies and applications of waste materials used as filler in partial or total substitution of raw materials for the production of HMAs [6]. One of the most productive activities related to construction field, in terms of wastes generated, is the Construction and Demolition (C\&D) one. A large part of the recycled fillers already used for HMAs is C\&D waste (i.e. concrete dusts, tiles and bricks powders) and many others are still under study. There have been many studies concerning the use of different industrial wastes as materials for the building sector. The literature review reports studies and applications of glass powder, bleaching clays, fly ashes, urban wastes and wastes from paper industries as filler to be used in HMAs [7-9]. It is worth noting that these are just few examples of researches with positive results, which show the increasing interest in substituting raw resources with wastes or second-hand materials. Following this line of research, the objective of the present study is to investigate the use of a Mining Waste Powder (MWP) as total replacement of mineral filler in HMAs. This paper shows the results of several laboratory tests carried out on bituminous mastics and asphalt mixtures to evaluate the effect of the use of MWP within common asphalt mixtures. Before being mixed with bitumen and aggregates, the MWP filler was characterised according to the EN 13043 standard, which specifies the properties of aggregates for road applications. For all tests and in every stage of research, results have been always compared to those obtained with a control mixture prepared with traditional limestone filler.

\footnotetext{
Corresponding author:piergiorg.tataranni2@unibo.it
} 


\section{Materials and methods}

\subsection{Aggregates and binder}

For research purpose, two different HMA mixtures for surface layers were prepared. Starting from the same aggregates gradation (Figure 1), the experimental mixture (labelled HMAMW) contains MWP in total substitution of traditional limestone filler, which was instead used for the production of the reference HMA (labelled HMALF). The design of the aggregates distribution was based on gradation limits specified in an Italian technical specification for bituminous top layers.

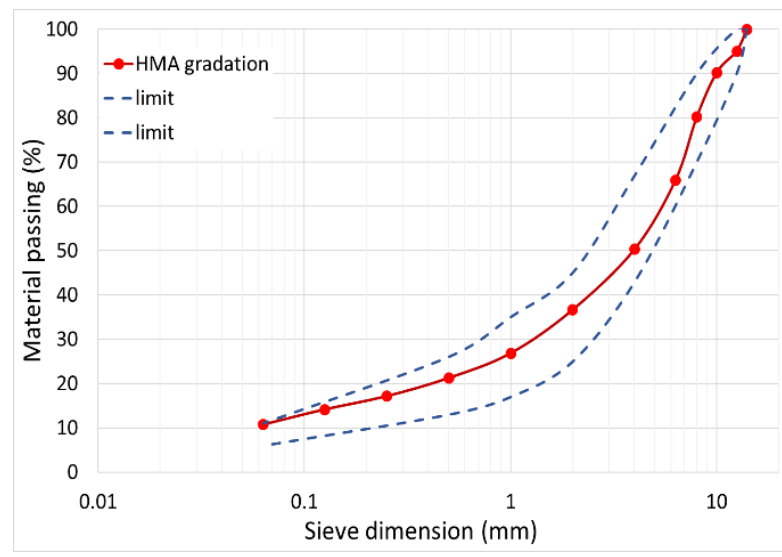

Fig. 1. HMA gradation and limits.

A standard 50/70 pen grade bitumen was used for the production of both mixtures. Table 1 summarizes the bitumen's rheological properties.

Table 1. Rheological properties of binder.

\begin{tabular}{|c|c|c|c|}
\hline Test & Unit & Value & Standard \\
\hline Penetration @ $25^{\circ} \mathrm{C}$ & $\mathrm{dmm}$ & $50-70$ & EN 1426 \\
\hline Softening Point & ${ }^{\circ} \mathrm{C}$ & 50 & EN 1427 \\
\hline $\begin{array}{c}\text { Dynamic Visc. } @ \\
60^{\circ} \mathrm{C}\end{array}$ & $\mathrm{Pa} \cdot \mathrm{s}$ & $\geq 145$ & EN 12596 \\
\hline Fraass & ${ }^{\circ} \mathrm{C}$ & -8 & EN 12593 \\
\hline
\end{tabular}

\subsection{Mining waste filler}

A Mining Waste Powder (MWP), which comes from the extraction activities in Panasqueira mines (Portugal), is used as filler in the present research. That is one of the oldest underground mine in Western Europe and today it is considered as one of the richest tungsten extraction sites in the world. During the years, a huge quantity of waste materials has been generated and nowadays from 100 to 200 tons of waste-rock tailings are daily produced. The considerable amount of these waste materials makes the area around the mine a problem for the environment and for the local population. In this regard, the on-going European research project REMINE (H2020 RISE-Marie Curie Action) is focusing on the potential use of Panasqueira mine wastes for the production of construction materials for transportation infrastructures [10]. In the present paper, MWP (Figure 2) is used in total substitution of traditional limestone (L) filler for the production of bituminous mixtures. The experimental filler is prepared from a mud, which is first dried and then powdered below 50 micron.

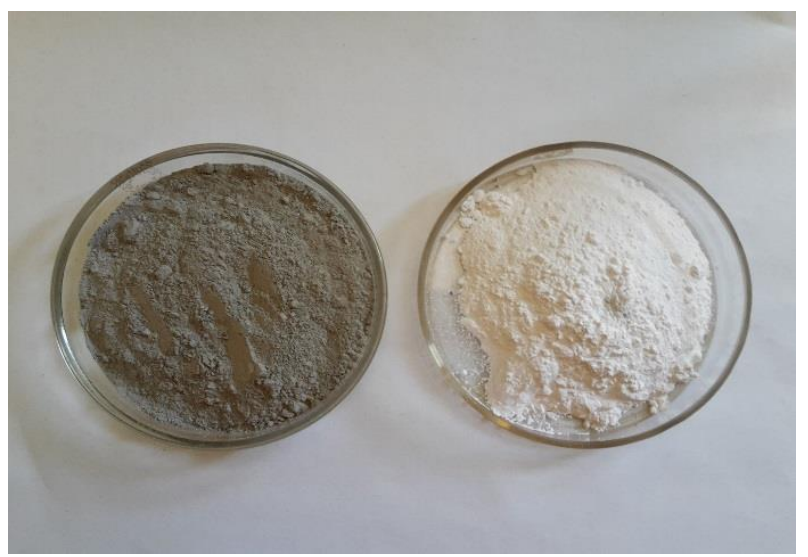

Fig. 2. MWP filler (left) and L filler (right).

\subsection{Test methods and experimental program}

The experimental program can be divided into three different phases. The first step was the physical and chemical characterization of MWP filler. The evaluation of MWP's properties was performed in compliance with EN 13043 standard. Data were always compared to those recorded for the traditional L filler. Fillers chemical composition was also assessed according to the Energydispersive X-ray Spectroscopy (EDS) method.

It is worth noting that the tests specified by the aforementioned standard are useful to describe the properties of fillers, but not sufficient to foresee the behaviour of the bituminous mastic and the asphalt concrete. In this regard, the second step of the experimental program was based on the rheological measurements and comparison of bituminous mastics containing MWP and L filler. The mastic proportions were assessed based on the HMAs mix design. In particular starting from the $5.3 \%$ of bitumen and $8.3 \%$ of filler in weight of aggregates, the obtained mastics were made up by $40 \%$ of bitumen and $60 \%$ of filler.

Mastics rheological tests were performed using an Anton Paar MCR302 Dynamic Shear Rheometer (DSR) with parallel plates configuration test. According to EN 14770 Amplitude Sweep and Frequency Sweep Tests were performed in order to evaluate mastic behaviour in the linear visco-elastic range. Multiple Stress Creep Recovery (MSCR) tests following the AASHTO TP 70-07 standard was implemented to analyse mastics permanent deformations resistance. Amplitude Sweep (AS) tests were performed to analyse the viscoelasticity field at 10 ${ }^{\circ} \mathrm{C}$, using a constant frequency of $10 \mathrm{rad} / \mathrm{s}(1.59 \mathrm{~Hz})$. FS tests were performed in a range of frequencies between 0.01 and $10 \mathrm{~Hz}$, at the temperatures of $0,10,20,30,40$, 50 and $60{ }^{\circ} \mathrm{C}$. Because of mastic stiffness, $8 \mathrm{~mm}$ plate with a $2 \mathrm{~mm}$ gap was used in all temperatures range. With the FS test the complex shear modulus $\left(\mathrm{G}^{*}\right)$ and the phase angle $(\delta)$ were measured. MSCR tests were performed on mastic samples loaded at a constant creep stress for $1 \mathrm{~s}$, followed by a zero stress recovery of $9 \mathrm{~s}$. Ten cycles of 
creep and recovery were run at $0.1 \mathrm{kPa}$ creep stress, followed by ten at $3.2 \mathrm{kPa}$ creep stress. The nonrecoverable compliance $\left(\mathrm{J}_{\mathrm{nr}}\right)$ and the percent recovery after ten cycles at 0.1 and $3.2 \mathrm{kPa}$ were assessed. The $\mathrm{J}_{\mathrm{nr}}$ value was calculated as the ratio between the average nonrecoverable strain for 10 creep and recovery cycles, and the applied stress for those cycles. The testing temperatures of 46,58 and $64{ }^{\circ} \mathrm{C}$ were investigated.

The third step of the research program was focused on tests on HMAs. Taking into account the different physical properties of MWP filler, if compared to the L one, the assessment of the optimum binder content needed. For each mixture, 9 Marshall specimens were prepared (EN 12697-30, 75 blows per side) with 3 different amounts of binder. Marshall tests were performed in compliance with EN 12697-34 standard on specimens conditioned in a water bath at $60{ }^{\circ} \mathrm{C}$ for $30 \mathrm{~min}$. The optimum bitumen content is related to the highest Marshall stability (EN 12697-34). The mechanical and physical characterization was then carried out just for specimens with optimized mix design. For both mixtures, Marshall specimens were produced and tested. Indirect Tensile Strength (ITS) at 25 ${ }^{\circ} \mathrm{C}$ (EN 12697-23) and air voids content analysis (EN 12697-8) were performed. Mechanical and physical results were always compared with values specified in an Italian technical specification for HMA for surface layers.

\section{Fillers properties}

The EN 13043 standard was followed to evaluate the physical and mechanical properties of MWP filler. The following test were performed:

- $\quad$ Size distribution (EN 10343);

- Water content (EN 1097-5);

- $\quad$ Particle density (EN 1097-7);

- Voids of dry compacted filler (EN 1097-4);

- Variation in "Ring and Ball" temperature (EN 13179-1);

- Harmful fines (EN 933-9);

- Water solubility (EN 1744-1).

Every test was repeated for both fillers. Moreover, the chemical composition of each filler was assessed by means of Energy-dispersive X-ray Spectroscopy (EDS). It is worth noting that the EN 13043 standard specifies some reference values for the aforementioned tests, but there are no restriction of use for fillers that do not respect them. The properties not in line with suggested values must be declared in the CE marking process. Table 2 summarizes the physical and mechanical results, while Table 3 shows the chemical composition of both materials.
Table 2. Physical and mechanical results for fillers.

\begin{tabular}{|c|c|c|c|}
\hline Test & Unit & $\begin{array}{l}\text { MWP } \\
\text { filler }\end{array}$ & $\begin{array}{c}\mathbf{L} \\
\text { filler }\end{array}$ \\
\hline Size distribution & $\begin{array}{c}\text { Passing } 63 \mu \mathrm{m} \\
(\%)\end{array}$ & 86 & 80 \\
\hline Water content & $\%$ & 0.18 & 0.20 \\
\hline Particle density & $\mathrm{Mg} / \mathrm{m}^{3}$ & 2.89 & 2.70 \\
\hline $\begin{array}{c}\text { Voids of dry } \\
\text { compacted filler }\end{array}$ & $\%$ & 28.1 & 41.0 \\
\hline $\begin{array}{c}\text { Variation in } \mathrm{R} \& \mathrm{~B} \\
\text { temperature }\end{array}$ & $\Delta \mathrm{T}\left({ }^{\circ} \mathrm{C}\right)$ & 8.1 & 8.0 \\
\hline Harmful fines & gMB/kg Filler & 3.3 & 6.7 \\
\hline Water solubility & $\%$ & 19.61 & 0.50 \\
\hline
\end{tabular}

Table 3. Chemical composition of MWP and L filler.

\begin{tabular}{|c|c|c|}
\hline Element & MWP filler (\%) & L filler (\%) \\
\hline $\mathrm{SiO}_{2}$ & 44.83 & 1.97 \\
\hline $\mathrm{CaO}$ & 0.00 & 98.03 \\
\hline $\mathrm{Al}_{2} \mathrm{O}_{3}$ & 18.39 & 0.00 \\
\hline $\mathrm{Fe}_{2} \mathrm{O}_{3}$ & 11.85 & 0.00 \\
\hline $\mathrm{SO}_{3}$ & 10.94 & 0.00 \\
\hline $\mathrm{ZnO}$ & 1.28 & 0.00 \\
\hline $\mathrm{K}_{2} \mathrm{O}$ & 3.62 & 0.00 \\
\hline
\end{tabular}

From the analysis of results, there are not significant differences between the two fillers apart for voids of dry compacted filler values and water solubility. For size distribution, both fillers comply with the standard suggested limit ( $70 \%$ passing the $63 \mu \mathrm{m}$ sieve). There are no significant differences between the fillers if the water content or the variation in $\mathrm{R} \& \mathrm{~B}$ temperature is considered. The values related to particle density are connected to fillers chemical and mineralogical compositions. If voids of dry compacted filler (Rigden voids, RV) are considered, MWP filler shows a lower value if compared to $\mathrm{L}$ filler. According to scientific literature, RV is an indicator of filler's property in absorbing bitumen. Moreover, it has a substantial influence on the stiffening power that the filler exercises on the bituminous mastic and, as a consequence, on the asphalt mixture $[11 ; 12]$. In the case under study, RV are equal to $28.1 \%$ for MWP filler. This value is in the range suggested by the EN 13043 standard (RV between 28 and $55 \%$ ). The methylene blue values (harmful fines test) are similar for both fillers, which can be classified as $\mathrm{MB}_{\mathrm{F}} 10$ according to the reference standard. As for water solubility, MWP shows a considerably high value if compared to the traditional L filler. In this case, EN 13034 standard suggest a reference value equal to $10 \%$. As for values presented in Table 3 , the chemical composition of both materials is evaluated in terms of percentage in weight of their oxides according to EDS method. Naturally, the high presence of calcium oxide for the limestone filler is related to its calcium carbonate composition. MWP filler is mainly composed of silicon dioxide and this is due to its mineralogical nature. 


\section{Bituminous Mastic results}

\subsection{Frequency Sweep}

In Figure 3 complex modulus and phase angle master curves of both studied mastics are represented. In all frequencies range the mastics behavior is the same. It is evident, from the linear visco-elastic analysis, that the MWP filler stiffening effects on the bitumen are the same of the $\mathrm{L}$ one. In terms of phase angle, both mastics show elastic response at low temperatures, visco-ealstic behavior at average temperatures and fully viscous deformation at high temperatures. Both fillers increase in the same way the stiffness of the bitumen but do not change the rheological properties in terms of visco-elastic response.

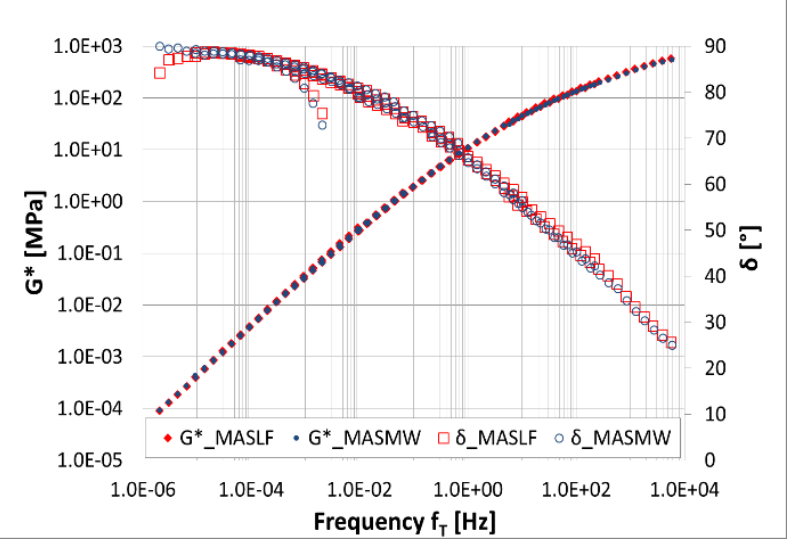

Fig. 3. Complex Modulus and Phase Angle master curves comparisons.

\subsection{Multiple Stress Creep Recovery (MSCR)}

In order to evaluate the accumulation of irreversible strains in the pavement top layer, the potential rutting of the mastics has been evaluated through Multiple Stress Creep Recovery (MSCR) tests run at 0.1 and $3.2 \mathrm{kPa}$. The average percentage of recovery and the non-recoverable compliance of ten cycles at $3.2 \mathrm{kPa}$ was evaluated following with the AASHTO TP 70-07 standard for each test temperature. Figures 4,5 and 6 show the results at the end of the 200th cycle at $3.2 \mathrm{kPa}$, respectively at 46,58 and $64^{\circ} \mathrm{C}$. The MASLF mastic containing traditional limestone filler shows considerable larger accumulated strains than MASMW for both shear stress conditions in all the temperature range. In particular, this result is more evident at 58 and $64^{\circ} \mathrm{C}$ where the accumulated strain difference between the two mastic increase from $33 \%$ to $70 \%$ with temperature increasing.

The rate of strain value increases and significantly changes when the $3.2 \mathrm{kPa}$ stress level starts: this effect is enhanced for the MASLF.

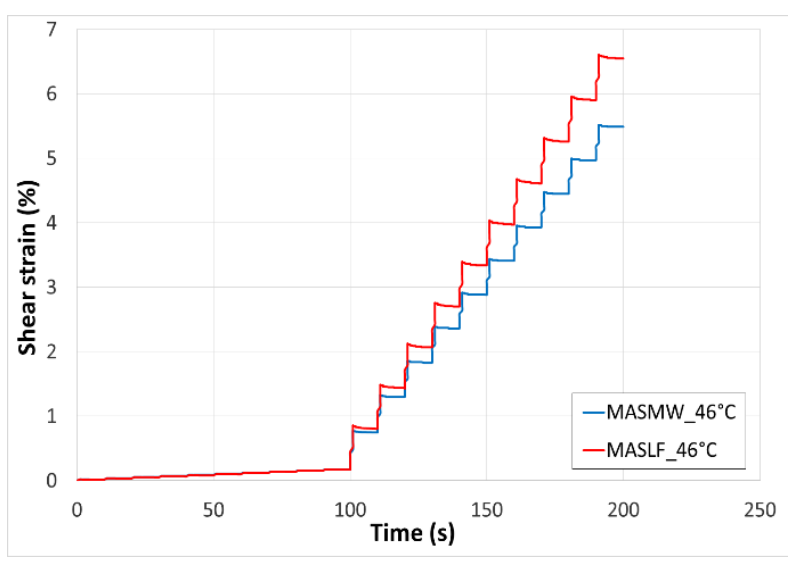

Fig. 4. MSCR results at $46^{\circ} \mathrm{C}$.

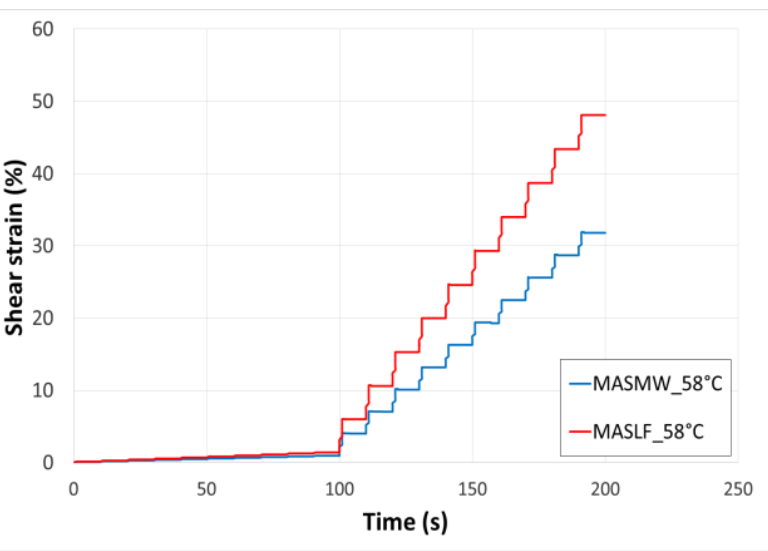

Fig. 5. MSCR results at $58^{\circ} \mathrm{C}$.

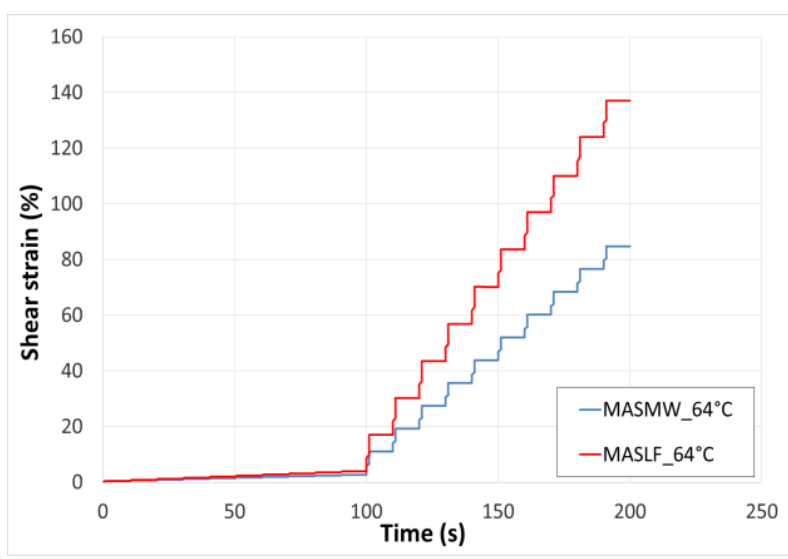

Fig. 6. MSCR results at $64{ }^{\circ} \mathrm{C}$.

Table 4 shows that the average recoverable strain of the two mastics is not significantly depending on the stress level. For both mastics, at $3.2 \mathrm{kPa}$ shear stress, the average percentage of recovery is $0 \%$, confirming the viscous behavior at high temperatures. As for the non-recoverable compliance values, mastics containing MWP filler have lower sensitivity to permanent deformation than mastics with limestone. In particular, at $3.2 \mathrm{kPa}$ and $64^{\circ} \mathrm{C}$ the mastic containing limestone filler shows a $\mathrm{J}_{\mathrm{nr}}$ value 1.6 times higher than the $\mathrm{J}_{\mathrm{nr}}$ obtained at the same conditions for the MASMW. 
Table 4. Avg. recoverable strain and non-recoverable compliance at $3.2 \mathrm{kPa}$.

\begin{tabular}{|c|c|c|}
\hline Specimen & $\begin{array}{c}\text { Average Recoverable } \\
\text { strain (\%) }\end{array}$ & $\mathbf{J}_{\mathrm{nr}}(\mathbf{1} / \mathbf{P a})$ \\
\hline MASMW_ $46^{\circ} \mathrm{C}$ & 0.56 & 0.16 \\
\hline MASLF_ $46^{\circ} \mathrm{C}$ & 0.43 & 0.19 \\
\hline MASMW_58 ${ }^{\circ} \mathrm{C}$ & 0.00 & 0.96 \\
\hline MASLF_58 $8^{\circ} \mathrm{C}$ & 0.00 & 1.46 \\
\hline MASMW_64 ${ }^{\circ} \mathrm{C}$ & 0.00 & 2.56 \\
\hline MASLF_64 ${ }^{\circ} \mathrm{C}$ & 0.00 & 4.16 \\
\hline
\end{tabular}

\section{Hot Mix Asphalt results}

\subsection{Optimum bitumen content}

The third step of the research program was focused on the mechanical and physical characterization of HMAs prepared with the traditional and the experimental fillers. Taking as a reference the aggregates gradation, the mix design phase was based on the determination of the optimum bitumen content according to the Marshall method (Marshall stability, EN 12697-34). Based on previous experimental application, for each mixture, three different binder contents were studied: 4.9, 5.3 and 5.7 \% (on aggregates weight). A total of 9 Marshall specimens were prepared for both mixtures (EN 12697-30, 75 blows per side). Marshall stability (EN 12697-34) is generally used for the evaluation of the optimum bitumen content. Samples were conditioned at $60{ }^{\circ} \mathrm{C}$ in a water bath for 30 min prior to testing. Average results are presented in Table 5 and shown in Figure 7.

Table 5. Marshall Stability test avg. results.

\begin{tabular}{|c|c|c|c|}
\hline Mixture & $\begin{array}{c}\text { Bitumen } \\
\mathbf{( \% )}\end{array}$ & $\begin{array}{c}\text { Stability } \\
\mathbf{( k N )}\end{array}$ & Flow (mm) \\
\hline HMAMW1 & 4.9 & 26.5 & 2.96 \\
\hline HMAMW2 & 5.3 & 27.3 & 3.00 \\
\hline HMAMW3 & 5.7 & 25.1 & 3.82 \\
\hline HMALF1 & 4.9 & 23.8 & 2.59 \\
\hline HMALF2 & 5.3 & 26.4 & 3.44 \\
\hline HMALF3 & 5.7 & 22.7 & 3.87 \\
\hline
\end{tabular}

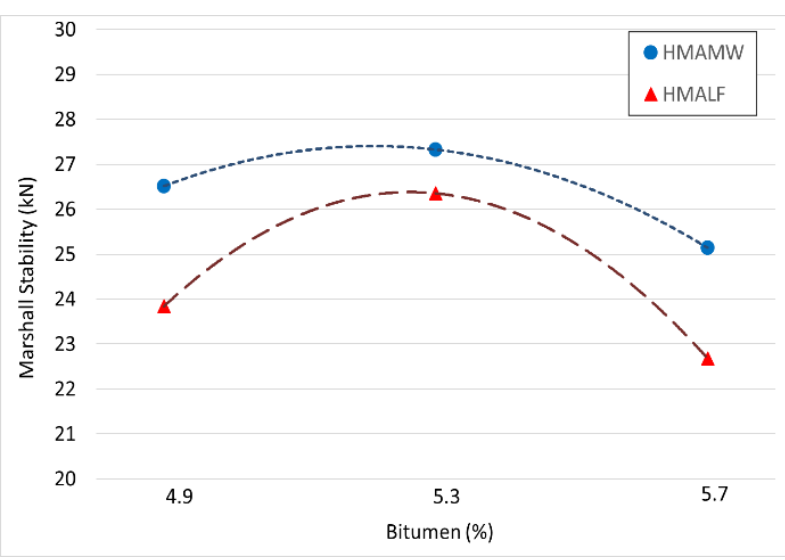

Fig. 7. Marshall Stability vs. Bitumen content.

According to tests results, the highest Marshall stability is recorded for mixtures produced with $5.3 \%$ of bitumen. It is worth noting that, according to the trend line for HMAMW mixture, the highest Marshall stability should correspond to a bitumen content equal to $5.2 \%$. This is mainly due to the lower absorption power verified for the MWP filler after RV test. However, for research purpose, the optimum binder content was fixed at $5.3 \%$ for both mixtures. From the analysis of results, HMAMW shows the highest Marshall stability. The value recorded for the experimental mixture with $5.3 \%$ of bitumen is more than double if compared to the stability limit specified in the Italian technical specification $(11 \mathrm{kN})$.

\subsection{Air voids content}

Once defined the correct mix design for both mixtures, the following step in the research program considered their physical analysis. The compactability and workability properties of the two different HMAs were evaluated on Marshall samples. For each mixture, 3 specimens were compacted with 75 blows per side. The air voids content (Va) of each specimen was evaluated following the EN 12697-8 standard. Results are shown in Table 6.

Table 6. Air voids contents.

\begin{tabular}{|c|c|c|}
\hline Specimen & $\begin{array}{c}\text { Air voids } \\
(\mathbf{\%})\end{array}$ & \multirow{2}{*}{$\begin{array}{c}\text { avg. Va } \\
\mathbf{( \% )}\end{array}$} \\
\hline HMAMW1 & 3.38 & \multirow{2}{*}{3.21} \\
HMAMW2 & 2.57 & \multirow{2}{*}{3.21} \\
\hline HMAMW3 & 3.68 & \\
\hline HMALF1 & 3.12 & \multirow{2}{*}{3.25} \\
\cline { 1 - 1 } HMALF2 & 3.05 & \\
\hline HMALF3 & 3.58 & \\
\hline
\end{tabular}

The two mixtures show comparable air voids contents. If the Italian technical specification is taken into account, the suggested Va content ranges between 3 and $4.5 \%$. In the light of the above, the use of MWP as filler does not seem to negatively affect the compactability and workability properties of the bituminous mixture.

\subsection{Indirect Tensile Strength test results}

The mechanical analysis was supported by the Indirect Tensile Strength (ITS) test in compliance with EN 12697 23 standard. For each HMA, 4 samples were prepared with Marshall compaction ( 75 blows per side) and then conditioned at $25^{\circ} \mathrm{C}$ for 4 hours before testing. According to the scientific literature, ITS test is generally used to assess the level of tenacity of aggregates-filler-bitumen bond. Results are presented in Table 7. From the analysis of data, there is no difference in terms of indirect tensile resistance between the two mixtures. The presence of MWP as filler within the bituminous mixture does not have any detrimental effect on this mechanical property. As a general remark, the average ITS recorded for HMAMW samples is considerably higher than the limit suggested by the Italian technical specifications (ITS > 0.7 MPa). 
Table 7. ITS results for HMAMW and HMALF.

\begin{tabular}{|c|c|c|c|}
\hline Specimen & $\begin{array}{c}\text { Max Load } \\
\text { (daN) }\end{array}$ & $\begin{array}{c}\text { Displacement } \\
(\mathbf{m m})\end{array}$ & $\begin{array}{c}\text { ITS } \\
\text { (MPa) }\end{array}$ \\
\hline HMAMW1 & 1256 & 1.78 & 1.53 \\
\hline HMAMW2 & 1325 & 1.36 & 1.55 \\
\hline HMAMW3 & 1288 & 1.45 & 1.55 \\
\hline HMAMW4 & 1355 & 1.36 & 1.63 \\
\hline avg. HMAMW & $\mathbf{1 3 0 6}$ & $\mathbf{1 . 4 9}$ & $\mathbf{1 . 5 6}$ \\
\hline HMALF1 & 1268 & 1.80 & 1.36 \\
\hline HMALF2 & 1321 & 1.70 & 1.52 \\
\hline HMALF3 & 1234 & 1.89 & 1.65 \\
\hline HMALF4 & 1289 & 1.75 & 1.65 \\
\hline avg. HMALF & $\mathbf{1 2 7 8}$ & $\mathbf{1 . 7 8}$ & $\mathbf{1 . 5 4}$ \\
\hline
\end{tabular}

If the vertical displacement is taken into account, it can be observed a small difference between the two mixtures. The average displacement recorded for HMAMW samples is $20 \%$ higher than the traditional HMA. These data confirm the results obtained from Marshall tests in terms of flows. The lower deformation could be related to the different stiffening power conferred by MWP filler to the bituminous mastic.

\section{Conclusions}

In the present research, a MWP was used for the production of bituminous mixtures for surface layers, in total substitution of the traditional $\mathrm{L}$ filler. To assess and to evaluate the experimental filler influence within HMAs, the research program was organized in three consecutive steps: the physical and chemical analysis of fillers, the rheological analysis of the bituminous mastics and the physical and mechanical characterization of HMAs. Based on the results obtained after each phase, the following conclusions can be drawn:

- If EN 13043 is taken into account, MWP filler has a gradation in line with the limit specified in the standard. There are no significant differences in terms of particles size between the experimental filler and the limestone one. Among all tests, RV value is significant since it could affect the physical and mechanical properties of the bituminous mixture. MWP shows a value in line with the lower limit suggested by the standard. As a general conclusion, there are no specific values for MWP, which does not comply with threshold limits specified in the EN 13043 standard. As for chemical analysis, previous researches underlined that a high calcium $(\mathrm{Ca})$ content into fillers is preferable for its significant interaction with bitumen. However, even if the EDS analysis confirmed the absence of Ca for MWP filler, this seems not to affect the interaction filler-bitumen as verified with variation in $R \& B$ temperature test.

- The study of the rheological properties of mastics containing L filler and MWP filler has shown that the presence of the waste powder does not influence bitumen rheological properties in terms of complex modulus and phase angle. The most interesting results is related to the analysis of permanent deformations in the non-linear field. In particular, from MSCR at $3.2 \mathrm{kPa}$ the mastic with MWP filler shows less sensitivity to permanent deformation with temperature rise.

- The study of the mix design confirms the good interaction of MWP filler with bitumen. The lower $\mathrm{RV}$ value determines a slight reduction in absorbed bitumen for HMAMW, as verified during the optimum binder content evaluation. Despite both mixtures were prepared with the same bitumen dosage, the presence of MWP filler did not affect the physical and mechanical properties of the HMAs. The air voids content analysis confirmed the good workability and compactability of the experimental mixture. Marshall stability and ITS were always higher, if compared to the reference mixtures. If the Italian technical specifications are taken as a reference, both volumetric and mechanical limit values are fully exceeded by the experimental mixtures $(3<\mathrm{Va}<4.5$; Marshall stability $>11 \mathrm{kN}$; ITS $>0.7 \mathrm{MPa})$.

Based on the experimental results presented in this paper, the use of MWP as filler in HMAs seems to be a viable solution for the production of eco-friendly bituminous mixtures. Further analysis on durability is needed to back these preliminary conclusions.

The present work was funded by the REMINE European project (H2020 RISE-Marie Curie Action).

\section{References}

1. CIA World Factbook (2015).

2. D. A. Anderson. Fourth annual aggregate symposium, Atalanta, (1996).

3. F.L. Roberts, P.S. Kandhal, D.Y. Lee. NAPA Research and education foundation, (1996).

4. M. Bocci, F. Giuliani. XXIII Convegno Nazionale Stradale AIPCR, (1998).

5. C. Sangiorgi, P. Tataranni, A. Simone, V. Vignali, C. Lantieri, G. Dondi. Construction and Building Materials, 138, (2017).

6. M.L. Alfonso, M. Dinis-Almeida, L.A. Pereira-deOliveira, J. Castro-Gomes, S.E. Zoorob. Construction and Building Material, 102, (2016).

7. S. Sargin, M. Saltan, N. Morova, S. Serin, S. Terzi. Construction and Building Materials, 48, (2013).

8. R. Melotti, E. Santagata, M. Bassani, M. Salvo, S. Rizzo. Waste Management, 33, (2013).

9. C. Sangiorgi, P. Tataranni, A. Simone, V. Vignali, F. Mazzotta, C. Lantieri. Coatings, 76, (2017).

10. C. Sangiorgi, C. Lantieri, P. Tataranni, C. Lantieri, J. Castro Gomes, M. Gabriel. Functional Pavement Design, CEW (2016).

11. C. Sangiorgi, P. Tataranni, A. Simone, V. Vignali, C. Lantieri, G. Dondi. Construction and Building Materials, 109, (2016).

12. F. Mazzotta, C. Sangiorgi, V. Vignali, C. Lantieri, G. Dondi. RILEM Bookseries, 11, (2015). 